P. Sindberg Eriksen, K. Rasmussen, E. Thorup

Department of Obstetrics and Gynecology,

Herlev Hospital,

DK-2730 Herlev, Copenhagen, Denmark.

The systolic slope of the blood velocity curve and the blood flow in the fetal thoracic aorta reflect the fetal cardiac function as well as the peripheral resistance. About half of the blood passing through the descending aorta will be distributed to the fetal part of the placenta which make this part of the circulation a target of special interest. The magnitude of the umbilical vein blood flow has been regarded as a measure of the functional state of the fetal-placental unit. By combining real-time linear array ultrasonic technique and pulsed Doppler ultrasound it has been possible to quantify blood flow in the fetal descending aorta and the umbilical vein (2). During the last five years the combined method has been widely used and the methodological errors and limitations has been evaluated and discussed $(2,5,13)$.

\title{
Clinical applications
}

Some discrepancy has been found between the descending aorta flow values in the third trimester of normal gestation largely explained by the use of different high pass filters $(5,9)$. The normal values, recently been reported, are ranging from $235.0 \pm 73.8 \mathrm{ml} / \mathrm{min} / \mathrm{kg}$ to $246.0 \pm 60 \mathrm{ml} / \mathrm{min} / \mathrm{kg}(5,9$, 10). The flow values obtained from the intraabdominal part of the umbilical vein has not been found to differ significantly between the different centers and are found to range from $98 \pm 52 \mathrm{ml} / \mathrm{min} / \mathrm{kg}$ to $122 \pm 42 \mathrm{ml} / \mathrm{min} / \mathrm{kg}$ (mean $\pm 2 \mathrm{SD})(2,4,5,6,10)$.

The method has been applied for pathophysiological studies in cases of intrauterine growth retardation. Conflicting results have been reported. JOUPPILA et al (6) found the blood flow in the umbilical vein below the normal range in $48 \%$ of the cases as a result of a narrowing of the vessel. No changes were found in respect to the mean blood flow in the descending aorta. GRIFFIN et al (5) found that thoracic aorta velocities fall within the lower limits or below the normal range in fetuses with growth retardation. GILL et al (4) found in 9 patients with severe oligohydramnios umbilical vein flow values below the normal range in all 5 infants, who later on where found to be light for gestational age. Higher flow values, on the other hand, has been found in pregnancies with pathological placentas suggesting that an impared placental function might be partly compensated by an increased blood flow (4).

An inverse relationship has been demonstrated between the blood flow in the umbilical vein and the postpartum hemoglobin concentration in the umbilical cord ( 8 ) and between the flow velocities in the thoracic aorta and the hematocrit in fetuses with severe rhesus isoimmunization (5). MARSAL et al (9) measured the aortic blood flow during labor in clinically normal pregnancies and found values similar to that in uncomplicated term pregnancies. No difference was demonstrated between patients with intact or ruptured membranes.

The waveform of the velocity curve is known to contain valuable information 
about the dynamic condition of the cardiovascular system. The slope of the ascending part of the curve is a measure of the cardiac contraction force, while the rate of deceleration and the end diastolic flow is an accepted measure of the peripheral resistance. The waveform has been found to change in a characteristic fashion with increasing gestational age, one of which were an increase in the velocity in end diastole in the latter part of the third trimester (5). STUART et al (12) using continous Doppler ultrasound found an increase in the ratio of peak systole to end diastole (the $A / B$ ratio) with advancing gestational age also indicating a decline in the placental resistance during the third trimester. By a similar technique, GILES et al (3) found that the resistance in the umbilical arteries is increased above the normal limit in growth retarded fetuses. This is in accordance with findings by GRIFFIN et al (5) demonstrating an increased pulsatility index (PI) in the descending aorta in pregnancies with poor fetal growth. The observation of an increased vascular resistance in pregnancies complicated with growth retardation is further supported by the finding of an increased pulse propagation velocity along the aorta in those fetuses (11) as an increased systemic blood pressure earlier has been found to increase the pulse wave velocity in the arteriel system. In this context an important observation was recently done by CAMPBELL et al (1). In pregnancies complicated with hypertension, poor fetal growth and hypoxia a raised vascular resistance was demonstrated also on the maternal side of the placenta.

The reactivity of the human fetal cardiovascular system has been investigated in response to the maternal smoking in two investigations using the pulsed Doppler method $(7,10)$. The two studies are mutual contradictory as in the one study (7) no changes in either the aortic or the umbilical vein flow were found. In this investigation (7), no changes in either the maternal or the fetal heart rates were found as expected from other studies. In the other study (10) a parallel increase in both the aortic blood flow velocity, the aortic diameter and also the mean blood flow was found within the first 20 min after smoking. This increase was followed by a similar increase in the umbilical blood flow by $55 \% 15$ to 25 min after cessation of smoking. This increase however, was a result of an enhanced vessel diameter and not an increased blood flow velocity suggesting a greater resistance in the placental circulation after smoking.

\section{Conclusion}

Determination of blood flow in the human fetal descending aorta and the umbilical vein by real-time scanner combined with a pulsed Doppler has proved to be a reliable method. The method is not only valuable in evaluating the distribution and the magnitude of the blood flow. The method has also proved the utility during dynamic condition, testing the reactivity of the fetal cardiovascular system. This might open new possibilities for testing the physiological or pathophysiological response of pharmacological agents for use in perinatal medicine.

Bibliography

( 1) CAMPBELL, S., J. DIAZ-RECASENS, D.R. GRIFFIN, T.E. COHEN-OVERBEEK, J.M. PEARCE, K. WILLSON, M.J. TEAGUE: New Doppler technique for assessing uteroplacental blood flow. Lancet i (1983) 675

( 2) EIK-NES, S.H., K. MARSAL, A.O. BRUBAKK: Ultrasound measurement of human fetal blood flow. J. Biomed. Engng. 4 (1982) 28 J.Perinat.Med. 12(1984) 
( 3 ) GILES, W.B., B.J. TRUDINGER, P.J. BAIRD: Antenatal assessment of placental flow resistance and placental microvascular anatomy. 10th Conference on Fetal Breathing Movements and Other Fetal Measurements. Malmö, Sweden 1983

( 4 ) GILL, R.W., P.S. WARREN, K.A. GRIFFITHS: Umbilical blood flow in high risk pregnancy. In: KURJAK, A., A. KRATCHOWIL: Recent Advances in Ultrasound Diagnosis 3. Excerpta Medica, Amsterdam (1981) 220

( 5) GRIFFIN, D., T. COHEN-OVERBEEK, S. CAMPBELL: Fetal and utero-placental blood flow. Clin. Obstet. Gynaecol. 10 (1983) 565

( 6) JOUPPILA, P., P. KIRKINEN, S.H. EIK-NES, A. KOIVULA: Fetal blood flow in growth retarded pregnancies. In: KURJAK, A., A. KRATCHOWIL: Recent Advances in Ultrasound Diagnosis 3. Excerpta Medica, Amsterdam (1981) 226

( 7) JOUPPILA, P., P. KIRKINEN, S.H. EIK-NES: Acute effect of maternal smoking on the human fetal blood flow. Br. J. Obstet. Gynaecol. 90 (1983) 7

( 8) KIRKINEN, P., P. JOUPPILA: Umbilical vein blood flow in rhesus-isoimmunization. Br. J. Obstet. Gynaecol. 90 (1983) 640

( 9) MARSAL, K., S.H. EIK-NES, A. LINDBLAD, G. LINGMAN: Blood flow in the fetal descending aorta; intrinsic factors affecting fetal blood flow, i.e. fetal breathing movements and cardiac arrhytmia. Ultrasound Med. Biol. in press

(10) SINDBERG ERIKSEN, P., K. MARSAL: Acute effects of maternal smoking on fetal blood flow. Acta obstet. Gynaecol. Scand. submitted

(11) SINDBERG ERIKSEN, P., G. GENNSER, K. LINDSTRÖM: Diameter pulse wave registration - A new method of investigation fetal circulation in utero. J. Med. Engng. Tech. submitted

(12) STUART, B., J. DRUMM, D.E. FITZGERALD, N.M. DUIGNAN : Fetal blood velocity waveforms in normal pregnancy. Br. J. Obstet. Gynaecol. 87 (1980) 780

(13) THORUP, E., P. SINDBERG ERIKSEN, K. RASMUSSEN: The Doppler ultrasound method for measurement of blood flow. J. Perinat. Med: 12 (1984) In press 